\title{
Fade Margin Estimations for Malaysian Armed Forces Military X-Band Satellite Communication Links
}

\author{
Abdullah 'Irfan Abdullah ${ }^{1}$, Ahmad Fadzil Ismail ${ }^{1}$, Khairayu Badron ${ }^{1}$ \\ and W. Hashim ${ }^{2}$ \\ Dept. of Electrical and Computer Eng., International Islamic University Malaysia \\ College of Computer Science \& Info. Tech., Universiti Tenaga Nasional Malaysia \\ abdullahirfan.abdullah@airforce.mil.my,af_ismail@iium.edu.my, \\ khairayu@iium.edu.my, andwahidah@uniten.edu.my
}

\begin{abstract}
The satellite communication (satcom) operating in X-band frequencies has the potential to enhance communication capabilities of Malaysian Armed Forces (MAF) and the Malaysian National Security Council (NSC). The satcom can be deployed during catastrophic instances, crisis incidences and certainly for the use of military operations. The satcom can facilitate the delivery of critical high-speed data, voice and video services between military bases, headquarters and also military detachments. The paper highlights the predicted fade margin requirements by the Malaysian Military satellite communication in order to accomplish specific operational quality of services (QoS). This is of utmost importance considering that both the uplink and the downlink will be facing severe rain attenuation due to copious heavy rainfall events, typically endured by tropical region countries. A prediction technique, recommendation ITU-R P.618-12 with value proposed by ITU-R P.637-6 had been employed in order to generate the desired results. Local data acquired from the Department of Irrigation and Drainage Malaysia had also been utilized in the generation of the fade margin estimations. The findings from the studies can offer insight of how to ensurelenhance the satellite communication links reliability.
\end{abstract}

Keywords: Rain attenuation, X-band, satcom, tropical region

\section{Introduction}

The communication operation of Malaysian Armed Forces (MAF) has been enhanced with the use of new satellite communication (satcom) links system operating at X-band frequencies. MAF previously leased satellite communication services from Telekom Malaysia Berhad operating at C-band frequencies. The high bandwidth requirement of MAF was facilitated by the MEASAT-3b satellite, built by Airbus Defence and Space SAS formerly known as Astrium. The MEASAT-3b was successfully launched on 12 September 2014. The satellite was launched into space using Ariana 5 ECA launch vehicle from the European Space Port located in Kourou French Guiana [1]. The satellite carries four dedicated X-band transponders including one with operating frequency of $8.12 \mathrm{GHz}$. The X-band payloads accommodate two coverage beams which are global and regional that offer peculiar advantages to MAF during their strategic and tactical operations. The satcom provides an improve long distance communications with adequate capacities to support effective operations of MAF. The system is controlled and monitored by the satellite Earth station designated as Pusat Komunikasi Satelit ATM which is located at Paya Jaras, Sungai Buloh, Selangor [2].

Received (August 15, 2017), Review Result (November 20, 2017), Accepted (November 26, 2017) 


\section{The Significance of Military X-band Satellite Communication}

The X-band frequencies have been traditionally reserved for military satcoms, in most countries around the world. The associated equipment for X-band satcom are expected to be designed specifically for military operations in term of improved mobility as well as their robustness. All communication links including the military are acutely subjected on sufficient access to the radio spectrum i.e. bandwidth. The bandwidth offered by X-band frequencies to date can sustain the interoperability requirement of multiple uniformed forces. At any time military utilization of the specific bandwidth facilitated by X-band frequencies must be safeguarded under joint effort campaign of both the civilian and military agencies. In Malaysia, Malaysian Communication and Multimedia Commissioner (MCMC) shoulders the role as the regulatory body for the whole nation. MCMC is the central regulatory body that overseeing communications and multimedia industry based on the authority warranted by the Malaysian Communications and Multimedia Commission Act passed by the parliament in 1998 [3] and another passed act in 2010 known as the Strategic Trade Act [4].

The conventional X-band satcom equipment are tactically designed to support smaller, low powered, easy to be assembled terminals intended to be deployed in all kind of operation theatres. The real push for X-band link is due to its wider bandwidths in contrast to the precursor S-band and C-band links. With wider bandwidths $\mathrm{X}$-band frequencies can certainly offer a more substantial increased capacity for the communication links. There are however, concerns regarding realization of X-band link in the tropics especially when taken into consideration specifications that particularly designed for operation in temperate climates. X-band frequencies operating in tropical regions will certainly have to endure higher attenuation because of atmospheric propagation losses and much more severe signal fading due to heavy rain [5]. On that note, accurate appraisal on challenges of an Xband link the case of tropical regions has to be carried out by satellite designers and engineers [6].

\section{System Location and Geographical Information}

The beacon signals are transmitted from MEASAT-3b satellite operating from its orbital slot at $91.5^{\circ} \mathrm{E}$. The overview scenario of MEASAT signal performance prediction is shown in Figure 3.1 above. The Earth station is located at Paya Jaras, Sungai Buloh Selangor at the longitude of $101.551^{\circ} \mathrm{E}$ and latitude of $3.206^{\circ} \mathrm{N}$. The above sea level height for the Earth station is approximately $0.063 \mathrm{~km}$. With reference to MEASAT-3b satellite, the earth station yields an antenna elevation angle of $77.55^{\circ}$. The rainfall rate readings are measured by an online monitoring system operated by Department of Irrigation and Drainage Malaysia (DID) at Kampung Paya Jaras Tengah, Sungai Buloh, Selangor installation site with the longitude of $101.32^{\circ} \mathrm{E}$ and latitude of $3.11^{\circ} \mathrm{N}$. 


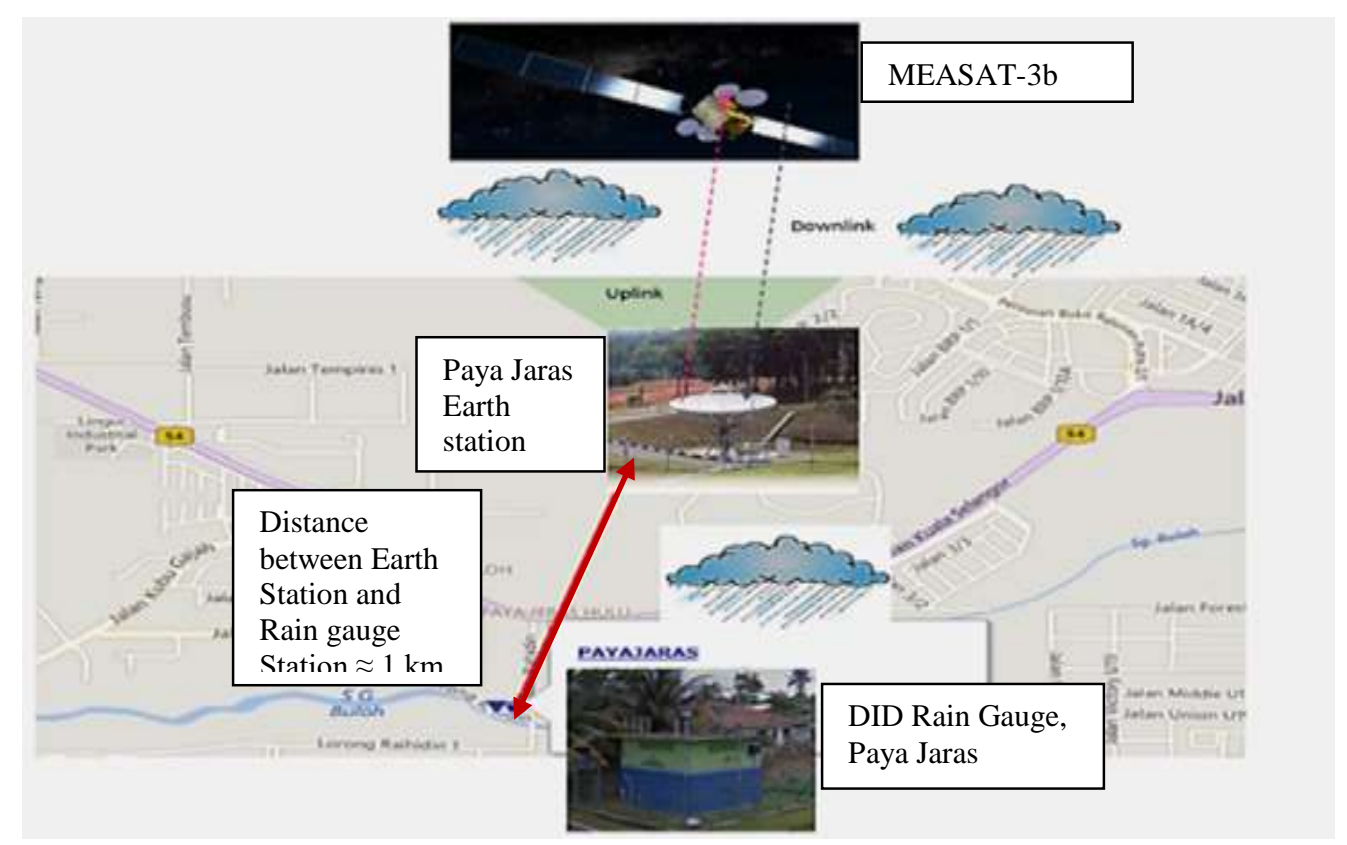

Figure 3.1. System Scenario

\section{Estimation Procedures}

The prediction of the attenuation experienced by beacon signal of X-band required diverse propagation parameter in the planning of Earth to space system operation or vice versa as shown in Table 4.1. The theoretical assessment for the newly established Earth station in Paya Jaras Selangor can be achieved using the following procedure.

Table 4.1. Earth Station and Satellite Information

\begin{tabular}{|c|c|}
\hline Paya Jaras Terminal Description & MEASAT-3b Satellite Location \\
\hline Longitude (degree), $l_{e s}: 101.551^{\circ} \mathrm{E}$ & Longitude (degree), $l_{s t}: 91.5^{\circ} \mathrm{E}$ \\
\hline Latitude (degree), $\varphi: 3.206^{\circ} \mathrm{N}$ & Frequency $(\mathrm{GHz}), f: 8.12$ \\
\hline $\begin{array}{c}\text { Above mean sea level's station } \\
\text { height }(\mathrm{km}), \mathrm{h}_{\mathrm{s}}: 0.063\end{array}$ & Polarization $:$ vertical \\
\hline
\end{tabular}

Rain fade margin at specific availability can be derived from predicted attenuation statistics for an average year. The rainfall rate $\mathrm{R}_{0.01}$, exceedance at $0.01 \%$ of an average year, both theoretically according to Recommendation ITU-R P.837-6 and locally measured had been applied in the ITU-R Model according to steps outlined in ITU-R P.618-12 [7][8]. Applicable local rainfall rates, $R_{0.01}$ with an integration time of $1 \mathrm{~min}$ had also been determined. Local measured rainfall rates at 5 minute integration was converted into values at 1 minute integration time using formulations by Segal and Burgueno [9]. The steps in generating the predicted attenuation levels are summarized below:

1) The rain height, $h_{R}$ was adopted using the proposed value in Recommendation ITUR P.839-4 [10]:

$$
h R=h 0+0.36 \mathrm{~km}
$$


2) If $\theta \geq 5^{\circ}$, the slant-path below the rain height length, $L_{s}$, was computed using equation:

$$
L_{S}=\frac{\left(h_{R}-h_{S}\right)}{\sin \theta} \quad \mathrm{km}
$$

Where rain height, $h_{R}$ was obtained from ITU-R P.839-4.

3) The slant-path length horizontal projection, $L_{G}$ was calculated as below:

$$
L_{G}=L_{s} \cos \theta \quad \mathrm{km}
$$

4) The specific attenuation, $\gamma_{R}$ was obtained by using the frequency-dependent coefficients made available by Recommendation ITU-R P.838-5 [11] and the rainfall rate, $R_{0.01}$, was determined from the previous step, by using:

$$
\gamma_{R}=k\left(R_{0.01}\right)^{\alpha} \quad \mathrm{dB} / \mathrm{km}
$$

5) The horizontal reduction factor, $r_{0.01}$, for $0.01 \%$ of the time was calculated as below:

$$
r_{0.01}=\frac{1}{1+0.78 \sqrt{\frac{L_{G} \gamma_{R}}{f}}-0.38\left(1-\mathrm{e}^{\left.-2 L_{G}\right)}\right.}
$$

6) The vertical adjustment factor, $v_{0.01}$, for $0.01 \%$ of the time was calculated as below:

$$
\zeta=\tan ^{-1}\left(\frac{h_{R}-h_{S}}{L_{G} r_{0.01}}\right) \quad \text { degrees }
$$

For $\zeta>\theta, \quad L_{R}=\frac{L_{G} r_{0.01}}{\cos \theta} \quad \mathrm{km}$

$$
\text { Else, } \quad L_{R}=\frac{\left(h_{R}-h_{S}\right)}{\sin \theta} \quad \mathrm{km}
$$

$$
\text { If }|\varphi|<36^{\circ}, \quad \chi=36-|\varphi| \quad \text { degrees }
$$

Else, $\quad \chi=0 \quad$ degrees

$$
v_{0.01}=\frac{1}{1+\sqrt{\sin \theta}\left(31\left(1-\mathrm{e}^{-(\theta /(1+\chi))}\right) \frac{\sqrt{L_{R} \gamma_{R}}}{f^{2}}-0.45\right)}
$$

7) The effective path length was determined:

$$
L_{E}=L_{R} v_{0.01} \quad \mathrm{~km}
$$

8) The predicted rain fade exceeded for $0.01 \%$ of an average year was obtained from:

$$
A_{0.01}=\gamma_{R} L_{E} \quad \mathrm{~dB}
$$


9) The estimated rain fade at other percentage exceedances of the average year, in the range $0.001 \%$ to $5 \%$, was ascertained from the rain fading to be exceeded for $0.01 \%$ for an average year:

$$
\begin{aligned}
& \text { If } p \geq 1 \% \text { or }|\varphi| \geq 36^{\circ}: \quad \beta=0 \\
& \text { If } p<1 \% \text { and }|\varphi|<36^{\circ} \text { and } \theta \geq 25^{\circ}: \quad \beta=-0.005(|\varphi|-36)
\end{aligned}
$$

Otherwise: $\quad \beta=-0.005(|\varphi|-36)+1.8-4.25 \sin \theta$

$$
A_{p}=A_{0.01}\left(\frac{p}{0.01}\right)^{\left.? 0.655+0.033 \ln (p)-0.045 \ln \left(A_{0.01}\right)-\beta(1-p) \sin \theta\right)} \mathrm{dB}
$$

Parameters were determined in accordance with the ITU-R's recommendation except with the inclusion of the rainfall rates generated using local measured values as shown in Figure 4.1. The parameters are listed in Table 4.2 below:

Table 4.2. Calculated Parameter Using ITU-R Recommendations

\begin{tabular}{|c|c|}
\hline Parameter & Values \\
\hline$R_{0.01}(\mathrm{~mm} / \mathrm{hr}) 5 \mathrm{~min}$ & 136 \\
\hline$R_{0.01}(\mathrm{~mm} / \mathrm{hr}) 1 \mathrm{~min}$ & $\begin{array}{c}\text { Segal[9], 156.4 } \\
\text { Burgueno [9], 157.8 }\end{array}$ \\
\hline$\theta\left(^{\circ}\right)$ & 77.58 \\
\hline$\tau\left(^{\circ}\right)$ & 72.21 \\
\hline $\mathrm{h}_{\mathrm{R}}(\mathrm{km}): \mathrm{ITU}-\mathrm{R}$ P.839-3 & 5.083 \\
\hline $\mathrm{L}_{\mathrm{s}}(\mathrm{km})$ & 5.14 \\
\hline $\mathrm{L}_{\mathrm{G}}(\mathrm{km})$ & 1.11 \\
\hline$k_{H}: \mathrm{ITU}-\mathrm{R} \mathrm{P} .839-3$ & 0.00754 \\
\hline$K_{V}: \mathrm{ITU}-\mathrm{R} \mathrm{P} .839-3$ & 0.00670 \\
\hline$\alpha_{H}: \mathrm{ITU}-\mathrm{R} \mathrm{P} .839-3$ & 1.3155 \\
\hline$\alpha_{V}: \mathrm{ITU}-\mathrm{R} \mathrm{P} .839-3$ & 1.2895 \\
\hline $\mathrm{A}$ & 1.303 \\
\hline $\mathrm{K}$ & 0.0071 \\
\hline$\gamma_{R}(\mathrm{~dB} / \mathrm{km})$ & 4.23346 \\
\hline$r_{0.01}(\mathrm{~mm} / \mathrm{hr})$ & 0.7980 \\
\hline$\zeta\left(^{\circ}\right)$ & 80.03316 \\
\hline$\chi\left(^{\circ}\right)$ & 32.7939 \\
\hline$v_{0.01}(\mathrm{~mm} / \mathrm{hr})$ & 0.4371 \\
\hline $\mathrm{L}_{\mathrm{R}}(\mathrm{km})$ & 4.1021 \\
\hline$A_{0.01}(\mathrm{~dB})$ & 6.38 \\
\hline $\mathrm{B}$ & 0.1639 \\
\hline
\end{tabular}




\subsection{Rainfall Rate at Paya Jaras Earth Station}

The monthly cumulative distributions functions (CDF) are grouped together for twelve consecutive months in 2016 shown in Figure 4.1. It can be observed that for measured rainfall rate, $\mathrm{R}_{0.01}$ exceed for $0.01 \%$ of an average year is $136 \mathrm{~mm} / \mathrm{hr}$ based on the annual CDF for 2016.

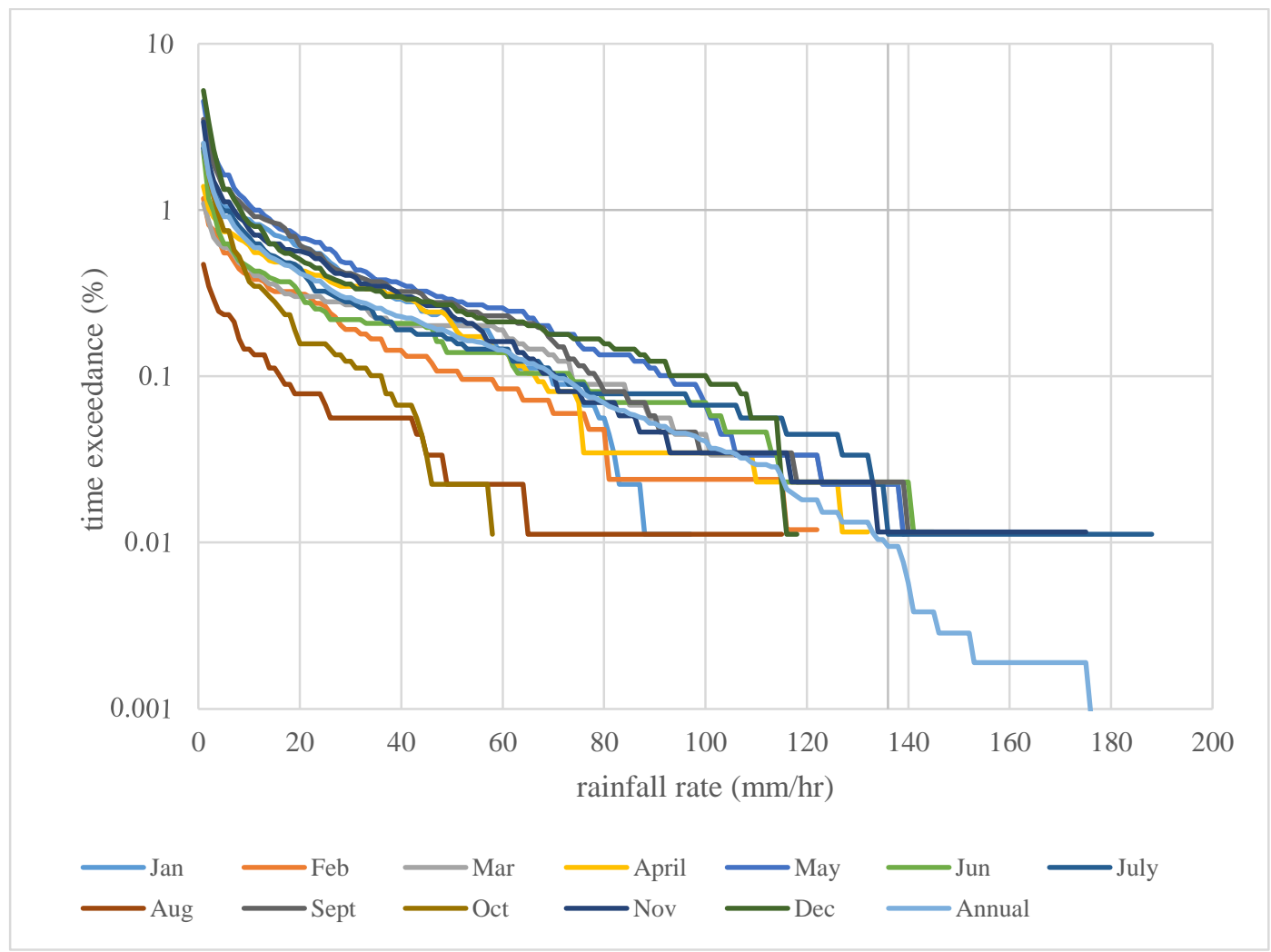

Figure 4.1. Monthly Distribution and Annual Distribution of Rainfall Rate at Paya Jaras Earth Station for the Year 2016

\section{Finding and Observations}

The communication links establishment should be planned based on the cumulative distributions. Cumulative distributions or annual statistic maybe the most practical presentation layout for the long-term data. The desired link performance can be achieved by incorporating applicable/suitable rain attenuation margin. The cumulative distribution functions of rain attenuation to be experienced at Paya Jaras Earth station were generated. The rain fade annual statistic produced using the ITU$\mathrm{R}$ recommendation; with ITU-R rain value as well as local data can be viewed from Figure 5.1. Table 5.1 shows select attenuation values for the X-band satellite-Earth link for specific MAF required QoS (broadcast- 0.3\%, communication - $0.03 \%$ ). 


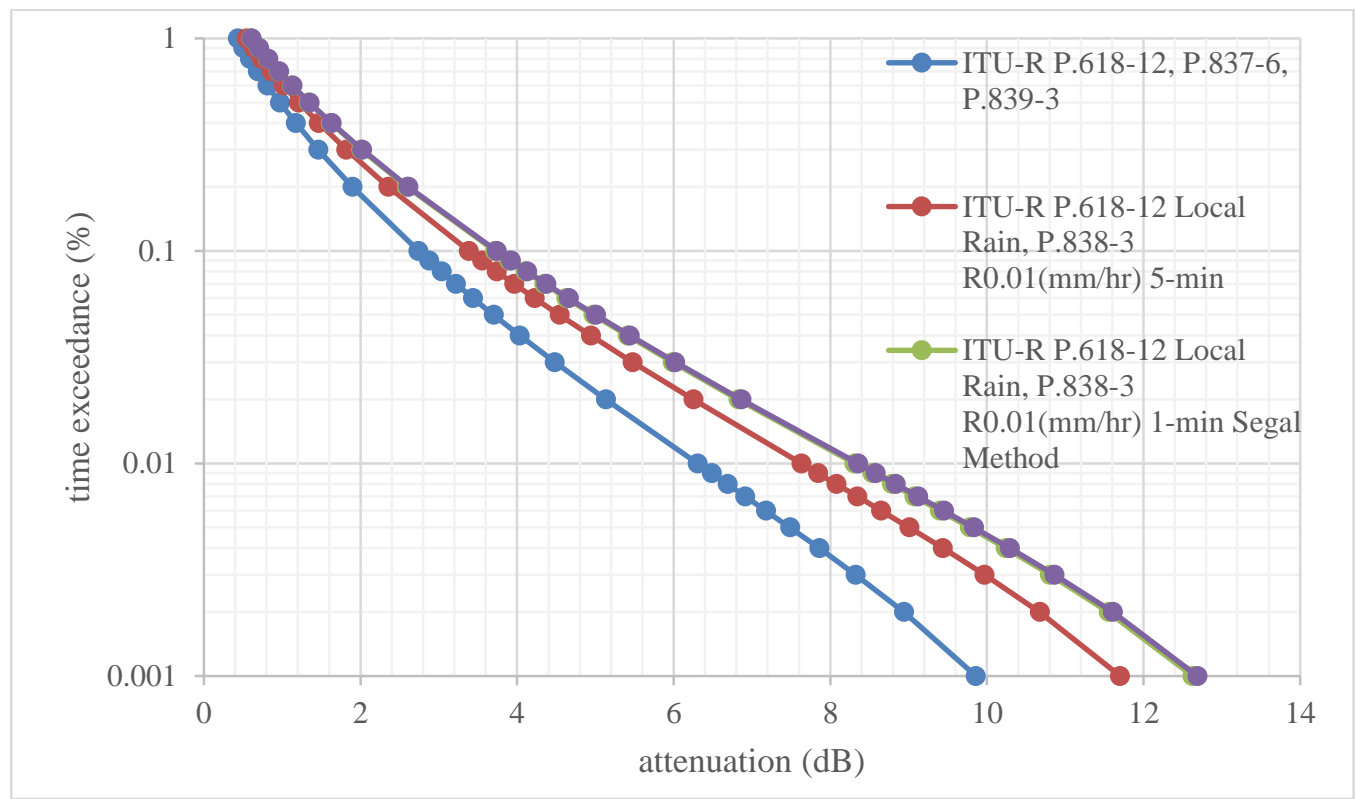

Figure 5.1. Plot of ITU-R Predicted Attenuation Statistics

Table 5.1. Selected Time Percentages and Predicted Values

\begin{tabular}{|c|c|c|c|c|}
\hline $\begin{array}{c}\text { Time } \\
\text { exceedance } \\
(\%)\end{array}$ & $\begin{array}{c}\text { ITU-R } \\
\text { Predicted } \\
\text { Attenuation } \\
(\mathrm{dB})\end{array}$ & $\begin{array}{c}\text { ITU-R with } \\
\text { local data } \\
\text { Predicted } \\
\text { Attenuation } \\
(\mathrm{dB})\end{array}$ & $\begin{array}{c}\text { ITU-R with } \\
\text { local data, } \mathrm{R}_{0.01} \\
(\mathrm{~mm} / \mathrm{hr}) \text { Segal } \\
\text { Method, } \\
\text { Predicted } \\
\text { Attenuation } \\
(\mathrm{dB})\end{array}$ & $\begin{array}{c}\text { ITU-R with } \\
\text { local data, } \mathrm{R}_{0.01} \\
(\mathrm{~mm} / \mathrm{hr}) \text { Segal } \\
\text { Method, } \\
\text { Predicted } \\
\text { Attenuation } \\
(\mathrm{dB})\end{array}$ \\
\hline 1.000 & 0.4316 & 0.6024 & 0.6061 & 0.6065 \\
\hline 0.300 & 1.4581 & 1.8175 & 2.0174 & 2.0174 \\
\hline 0.100 & 2.7377 & 3.3804 & 3.7355 & 3.7355 \\
\hline 0.030 & 4.4772 & 5.4714 & 6.0165 & 6.0165 \\
\hline 0.010 & 6.3016 & 7.6285 & 8.3502 & 8.3509 \\
\hline 0.001 & 9.8557 & 11.6970 & 12.6849 & 12.6853 \\
\hline
\end{tabular}

\section{Conclusion}

The military X-band satellite communication for Malaysian Armed Forces are in operation. The reliability of $\mathrm{X}$-band link is indeed becoming very critical where highspeed data, voice and video transmission can be affected by the rain fade. The feasibility studies on the impairment identify that consequences are indeed quite damaging due to the fact that Malaysia experiences tropical climate. Preliminary results of possible rain induce-attenuation signal degradation to be experienced by the $\mathrm{X}$-band satcom link at Paya Jaras had been predicted. In general, the X-band satellite operation in Malaysia may have difficulties to achieve the $99.99 \%$ availability (equivalent to $0.001 \%$ time exceedance) this is due to the fact that considerable substantial margin of more than $10 \mathrm{~dB}$; has to be incorporated in order to cope with rain fading in such severe climate. The differences between ITU-R prediction and with local data is approximately $2 \mathrm{~dB}$. For future works, annual CDF generated using 24 months or two years of rainfall rate will be pursued. 


\section{Acknowledgments}

The authors express thanks the Research Management Centre of International Islamic University Malaysia (IIUM) for the financial assistance and would like to express special appreciation to Malaysian Armed Forces of MATM-Bahagian Komunikasi dan Elektronik (KOMLEK) for the technical guidance and assistance in the collaboration that makes the analysis possible.

\section{References}

[1] MEASAT-3b Successfully Launched. [Online]. Available: http:// www.measat.com/pdf/press/2014/pr1209.pdf.

[2] MAF Moves A Step Further With Own Satellite. [Online]. Available: http:// www.bernama.com /bernama/v6/newindex.php?id=925049

[3] Malaysian Communications and Multimedia Commission Act 1998 (Act 598)" (PDF). Laws of Malaysia. Attorney's General Chambers of Malaysia. 2006. Retrieved 30 September 2014.

[4] Strategic Trade Act 2010 (Act 708)" (PDF). Atomic Energy Licensing Board. 2006. Retrieved 30 September 2014.

[5] J. E. Allnutt and P. Peregrinus, "Satellite-to-ground radiowave propagation: Theory, practice, and system impact at frequencies above $1 \mathrm{GHz}$ ", (1989).

[6] A. C. M. Nuroddin, A. F. Ismail, K. Abdullah, K. Badron, M. Ismail and W. Hashim, "Rain Fade Estimation for the X-Band Satellite Communication Link in the Tropics", International Journal of Computer and Communication Engineering, vol. 2, no. 4, (2013) July.

[7] Recommendation ITU-R P.837-6, "Characteristics of precipitation for propagation modeling", ITU-R P Sers, Int. Telecomm. Union, Geneva, (2012).

[8] Recommendation ITU-R P.618-12, "Propagation Data and Prediction Methods Required for the Design of Earth-space Telecommunication Systems", ITU-R P Sers., Int. Telecomm. Union, Geneva, (2015).

[9] M. H. Khairolanuar, A. F. Ismail and A. Z. Jusoh, "Assessment of empirical conversion methods for producing 1-min integration time rainfall rate in Malaysia", 2014 IEEE 2nd International Symposium on Telecommunication Technologies (ISTT), Langkawi, (2014), pp. 394-397.

[10] Recommendation ITU-R P.839-4, "Rain height model for prediction methods", ITU-R P Sers., Int. Telecomm. Union, Geneva, (2013).

[11] Recommendation ITU-R P.838-5, "Specific attenuation model for rain for use in prediction methods", ITU-R P Sers., Int. Telecomm. Union, Geneva, (2005).

[12] R. S. Tomar and G.S. Tomar, "Efficiency Enhancement Techniques for Wireless Communication Systems", International Journal of Systems Simulation and Systems, vol. 11, no. 1, (2010) December, pp. $41-47$.

\section{Authors}

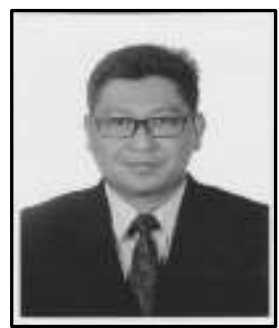

A. I. Abdullah is a Ph.D. candidate in Communication Engineering at Electrical and Computer Engineering Department, IIUM. He is a Royal Malaysian Air Force Engineer and received his bachelor degree in Communication Engineering from IIUM in 2006. He pursued his MSc. in Telecommunication and Information Engineering, UiTM in 2016. His research interests are satellite communication particularly related to X-band frequencies as well as radar systems.

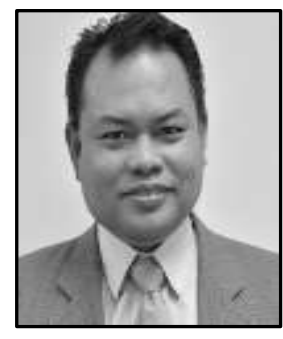

A. F. Ismail is Deputy Dean at Research Management Centre, IIUM. He completed his bachelor degree studies in Electrical Engineering at Gannon University, Pennsylvania, USA with Cum Laude Latin honors. He holds MSc from the University of Essex, UK and Ph.D. from University of Bath, UK. His research interests including the millimeter and microwave propagation studies and Cognitive Radio applications. He is a registered Professional Engineer with Board of Engineering Malaysia and also a Senior Member of the IEEE. 


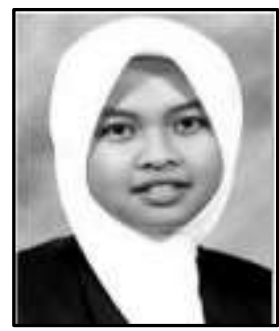

K. Badron obtained her BEng, MSc. and Ph.D. from International Islamic University Malaysia (IIUM) in 2006, 2011 and 2016 respectively. She is currently one of the assistant Professor at the Faculty of Engineering. Her research areas are in Radar Radiometry research, satellite communication and navigations, and quantifying propagation effects on microwave and millimeter links. She is a member of MTSFB, IEM, BEM and IEEE. She has published and coauthored more than thirty papers in indexed Journals as well as Conferences on subjects relating to rain attenuation in the tropical regions.

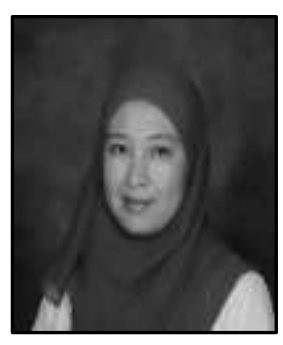

W. Hashim received her bachelor degree in Information Technology, Business Management and Language from University of York, UK in 1999. She then pursued her MSc in Multimedia Technology at University of Bath, UK in 2001. She completed her PhD studies from King's College London, UK in 2008 in the field of Telecommunication Engineering. She is currently at Universiti Tenaga Nasional, System and Networking Department, College of Computer Science and Information Technology as a principle lecturer since 2014. Prior to this, she was a staff researcher at MIMOS Berhad, a Malaysian National R\&D in ICT sector. Apart from her main task in doing research in cognitive radio, WLAN, OFDM, MIMO systems, IoT, Big Data and wireless system, she is actively involved in the development of Malaysia technical specification, standard and guidelines of wireless devices, International Mobile Telecommunication (IMT) systems and sensor network for Malaysian Communications and Multimedia Commission (MCMC). 
International Journal of Future Generation Communication and Networking Vol. 11, No. 3 (2018) 